Revista ADM.MADE - Revista do Mestrado em Administração e Desenvolvimento Empresarial

Universidade Estácio de Sá - Rio de Janeiro

ISSN 2237-5139

\title{
Velha é a vovozinha: uma análise interpretativa do consumo e estigma associado à identidade de idade de mulheres após os 65 anos
}

\author{
Ruane Pereira Cordeiro ${ }^{1}$ \\ Severino Joaquim Nunes Pereira ${ }^{2}$ \\ André Henrique Sousa Barros ${ }^{3}$ \\ Natassia de Melo Gomes ${ }^{4}$
}

\begin{abstract}
A terceira idade está crescendo interessada em consumir diversos produtos e serviços, como viagens, restaurantes e cursos, mas o mercado associa, a esses indivíduos, o estereótipo negativo da idade, como os de que são doentes, debilitados e incapazes. Além disso, difunde a ideia de que os sinais do envelhecimento devem ser postergados pelas mulheres, pois as marcas do tempo no corpo são consideradas estigma visíveis. Diante disso, o mercado constrói identidade estigmatizada sobre a terceira idade. Com o objetivo de analisar como mulheres entre 65 e 75 anos lidam com o estigma associado à identidade de idade por meio de suas práticas de consumo, a presente pesquisa relaciona-se à vertente da Consumer Culture Theory (CCT) que considera que o mercado dispõe de recursos materiais e simbólicos que, quando apropriados pelos indivíduos, os auxiliam na construção das suas identidades. A pesquisa foi realizada por meio de entrevista em profundidade com 11 mulheres da região metropolitana do Rio de Janeiro, e as evidências foram analisadas por meio da análise de conteúdo. Os resultados apontam que há um enfrentamento à identidade de idade construída socialmente, relacionada ao estereótipo negativo de dependência, de doença, de debilidade e de feiura.
\end{abstract}

Palavras-chave: consumo, identidade de idade, estigma.

Old is your grandmother: an interpretative analysis of the consumption and stigma associated with the age identity of women after 65 years

\begin{abstract}
The aged population is growing and they are interested in consuming various products and services, such as travel, restaurants and courses, but the market tends to associate this target with negative stereotypes of age such as being sick, debilitated, and disabled. In addition, the market disseminates the idea that the signs of aging should be postponed by women, because age marks on the body are considered a stigma symbol. As a consequence, we have a scenario in which the market builds on the elderly a stigmatized age identity. The focus of this research is related to the Consumer Culture Theory (CCT), which considers that the market has material and symbolic resources that enables individuals to construct their identities. The objective of this research is to analyze how women between 65 and 75 years old deal with the stigma associated with age identity through their consumption practices. The research was conducted through an in-depth interview with eleven women from the metropolitan region of Rio de Janeiro, data were analyzed through content analysis. Results indicate that there is a resistance to the dominating patterns of socially constructed age identity that is related to the negative stereotype of dependence, disease, weakness and ugliness.
\end{abstract}

Keywords: consumption, age identity, stigma.

\footnotetext{
${ }_{1}$ Mestre em Administração pela Universidade Federal Rural do Rio de Janeiro (UFRRJ). Programa de Pós-Graduação em Administração - Mestrado Acadêmico em Administração (PPGA - MAA). E-mail: ruane.cordeiro@gmail.com.

2 Doutor em Administração pela Escola Brasileira de Administração Pública e de Empresas da Fundação Getúlio Vargas - EBAPE/ FGV - RJ. Professor do Programa de Pós-Graduação em Administração Acadêmica da Universidade Federal Rural do Rio de Janeiro - PPGA/MAA. Departamento de Administração e Turismo (IM-DAT). E-mail: Bill.pereira4@gmail.com.

${ }^{3}$ Mestre em Administração pela Universidade Federal Rural do Rio de Janeiro (UFRRJ). Professor de Graduação de Contabilidade pela Universidade Federal Fluminense (UFF). E-mail: andrehbarros1@gmail.com.

${ }^{4}$ Mestre em Gestão e Estratégia pela Universidade Federal Rural do Rio de Janeiro (UFRRJ). Programa de Pós-Graduação em Gestão e Estratégia (PPGE). E-mail: natassiagomes@hotmail.com.
} 


\section{Introdução}

O Brasil tem apresentado crescimento no número de indivíduos na terceira idade. No decêndio entre os anos de 2001 e 2011, seu número de pessoas com idade igual ou superior aos 60 anos saltou, de 18,6 milhões, para 23,5 milhões (IBGE, 2012). Além disso, a maior parte dessa população é composta por mulheres, cuja expectativa de vida de 78,5 anos em 2013 superava os 71,2 anos estimado para os homens (IBGE, 2014). Esses dados evidenciam a necessidade de a terceira idade ser tratada também como uma questão de gênero (SANT'ANNA, 1997). Mesmo com o aumento dessa população e diante do reconhecimento do impacto social da terceira idade, o cenário de estigmatização sofrido pela terceira idade é mantido e reforçado pelo mercado. Nas comunicações de Marketing, por exemplo, quase não são apresentados indivíduos nessa faixa etária, e, quando eles aparecem, geralmente são representados de maneira estúpida, débil ou divertida (QUEZADO; MATOS; SOUZA, 2014; SZMIGIN; CARRIGAN, 2001). Sendo-Ihes direcionados produtos mais relacionados à incapacidade de locomoção, constrói-se imagem de que os consumidores na terceira idade são debilitados e doentes (BALLSTAEDT, 2007).

Além disso, o mercado difunde a ideia de que os sinais do envelhecimento no corpo devem ser postergados por meio do consumo de produtos e serviços estéticos. Impactando especialmente as mulheres, isso gera imagem negativa sobre a terceira idade em virtude da não aceitação da sua aparência. Assim, as marcas do tempo no corpo são consideradas símbolo de estigma (CARDOSO, 2007; GOFFMAN, 2004).

Diante disso, com o apoio dos significados atribuídos ao consumo, sobre a terceira idade o mercado constrói identidade socialmente construída e estigmatizada. Essa, no entanto, pode ser recusada por esses indivíduos (BARNHART; PEÑALOZA, 2013).

O foco da presente pesquisa é a construção de identidades por meio do consumo, investigação relacionada à perspectiva da Consumer Culture Theory (CCT), que leva em consideração que o mercado dispõe de recursos materiais e simbólicos que, quando apropriados pelos indivíduos, os auxiliam na construção das suas identidades (BELK, 1988; ARNOULD; THOMPSON, 1995). Seu objetivo é analisar como mulheres com idades entre 65 e 75 anos lidam com o estigma associado à identidade de idade por meio de suas práticas de consumo.

Esse esforço ampliará o conhecimento sobre o segmento da terceira idade, em especial de mulheres. Mostrará como essas consumidoras constroem sua identidade de idade ao revelar o que pensam, como se sentem com relação ao envelhecimento, e como enfrentam o estigma social da identidade de idade por meio dos significados atribuídos ao consumo. Servirá também para revisão mais crítica dos estereótipos negativos que ainda permanecem sobre a terceira idade.

Ademais, levantamento da literatura mostrou que nenhuma das pesquisas encontradas voltadas à análise do segmento de consumidores da terceira idade, nos contextos tanto norte-americano quanto brasileiro, se propôs a investigar a relação entre o estigma associado à terceira idade e sua consequência no consumo e na construção da identidade de idade.

Exemplos dessa lacuna podem ser encontrados em Barnhart e Peñaloza (2013), que analisaram a negociação da identidade de idade de consumidores idosos; em Schau, Gilly e 
Wolfinbarger (2009), que investigaram a construção da identidade do consumidor na aposentadoria; em Kelly, Ribas e Costa (2010), que identificaram os valores dos consumidores da terceira idade nos serviços de atividades física, educativa e dança; e em Rosenthal e Brito (2015), que investigaram a prática da corrida como uma importante atividade na construção identitária de indivíduos maduros e da terceira idade.

\section{Fundamentação Teórica}

\subsection{Cultura, consumo e identidade}

Cultura, consumo e identidade possuem forte inter-relação no mundo contemporâneo. Quando são feitas escolhas de consumo não ocorre apenas a apropriação do valor utilitário do bem ou a afirmação de uma preferência, mas também a revelação de uma identidade para o mundo (BARBOSA; CAMPBELL, 2006).

Isso ocorre porque os bens são classificados em categorias culturais que, por exemplo, determinam o que é apropriado ao consumo de homens e mulheres em termos de cor, de forma, de tamanho de roupa. Determinam também o que, como e quando se deve comer. Assim, a partir da apropriação dos significados atribuídos aos bens no consumo, os indivíduos podem construir e comunicar suas identidades (BELK, 1988; McCRAKEN, 2003).

Os bens de consumo sempre tiveram significados culturais e foram utilizados para reproduzir identidades sociais; porém, o que marca a sociedade atual é que as relações sociais, os valores e ideais compartilhados, bem como as identidades, são mais fortemente orientados pelo consumo (SLATER, 2002). Ou seja, atualmente a sociedade é organizada em termos da cultura de consumo, que pode ser definida como "um arranjo social em que a relação entre a cultura vivida e os recursos sociais, entre modos de vida significativos e os recursos materiais e simbólicos dos quais dependem são mediados pelos mercados" (ARNOULD; THOMPSON, 2005, p.869).

Portanto, o consumo desempenha papel importante na construção das identidades dos indivíduos, pois eles procuram expressar e confirmar quem são por meio de suas posses (BARNHART; PEÑALOZA, 2013; BELK, 1988; PEREIRA; AYROSA, 2012). Nesse sentido, é importante ressaltar que, atualmente, indivíduos e grupos não ordenam suas vidas por meio apenas das categorias sociais tradicionais - como etnia, sexo, idade, valores, classe social mas podem criar suas próprias categorias, formando subculturas por meio de suas escolhas de consumo (SCHOUTEN; McALEXANDER, 1995). Por exemplo, os fãs da série Star Trek criam subculturas a partir dos ideais utópicos ali presentes: eles combinam interesses, fantasias, valores e habilidades com práticas de consumo e com significados de certos textos, imagens e objetos do seriado (KOZINETS, 2001).

Além disso, os indivíduos constroem identidade por meio da apropriação do discurso do mercado e de sua interpretação em relação aos objetivos pessoais do indivíduo (THOMPSON; HYTKO, 1997). Assim fizeram, por exemplo, as consumidoras e blogueiras plus size $^{5}$, marginalizadas pelo mercado, ao construírem uma identidade coletiva e se

\footnotetext{
${ }^{5}$ Termo utilizado para se referir a pessoas grandes que usam roupas nos tamanhos 12 a 24 , no padrão da indústria da moda americana.
} 
autointitularem fatshionistas para reivindicar, do mercado dominante, o fornecimento de mais opções de roupas da moda em tamanho plus size (SCAROBOTO; FISHER, 2013).

E ainda, como será abordado na presente pesquisa, por meio dos significados atribuídos às práticas de consumo é possível negar ou enfrentar o julgamento social sobre a identidade imposta a indivíduos e a grupos que se enquadram em determinada categoria cultural - como no caso dos indivíduos da terceira idade, que têm identidade estigmatizada (BARNHART; PEÑALOZA, 2013; GOFFMAN, 2004).

\section{2. $O$ consumidor na terceira idade}

A identidade é resultado dos intercâmbios sociais entre indivíduos e grupos, e dos mecanismos de diferenciação e de identificação estabelecidos entre eles. Portanto, a identidade é um modo de categorizá-los (CUCHE, 1999). Woodward (2000) enfatiza esse ponto ao afirmar que os discursos e os sistemas de representação são construídos e produzem significados que ajudam os indivíduos a se posicionarem e a se identificarem no mundo.

Assim, por exemplo, a identidade de gênero é construída para diferenciar a mulher do homem, e a de idade para diferenciar os jovens dos velhos. Vale destacar que essas categorias discursivas são uma forma de categorizar e controlar os indivíduos (FOUCAULT, 1999). Exemplo disso surge no trabalho de Pereira e Ayrosa (2012), que demonstra como a categoria homossexual de determinado grupo gay carioca se opõe à categoria heteronormativa dominante.

Nesse sentido, pode-se dizer, ainda, que a medicina foi a precursora do discurso identitário da terceira idade. Isso porque, no fim do século XIX e início do XX ela construiu discurso que associava o processo de degradação do corpo, as doenças biológicas e a morte à categoria etária hoje denominada terceira idade (SILVA, 2008). Além disso, culturalmente, em virtude da perda do papel social de trabalhador e da entrada na aposentadoria, a terceira idade geralmente é associada a declínio, feiura, dependência, empobrecimento, improdutividade e perda do indivíduo (ROSENTHAL; BRITO, 2015).

Tais significados contribuem para que a identidade de idade da terceira idade seja socialmente estigmatizada; ou seja, os indivíduos que se enquadram nessa categoria não são plenamente aceitos em sociedade por lhes serem atribuídas características negativas (GOFFMAN, 2004).

Atualmente, pode-se considerar o mercado como instância produtora de discursos e de representação sobre a terceira idade, ao posicioná-la de acordo com a maneira como a sociedade geralmente pensa que ela se comporta e deve se comportar, produzindo categorias sociais, e impondo identidade com determinadas características, capacidades e limitações (BARNHART; PEÑALOZA, 2013). No entanto, esse posicionamento tem sido contestado e até mesmo rejeitado pelos consumidores da terceira idade na construção de sua identidade etária (BARNHART; PEÑALOZA, 2013).

Por exemplo, já na década de 1980 os indivíduos que estavam na terceira idade tinham níveis de sensibilização para muitas tecnologias, descoberta que contrariava o que a literatura existente poderia prever, dada a tradição de os ver como resistentes a mudanças (GILLY; ZEITHAML, 1985). 
Da mesma forma, a maioria dos informantes de terceira idade pesquisados por Quezado, Matos e Souza (2014) a respeito de sua percepção a comercial da Brastemp veiculado em 2003 que apresentava o idoso com problema de deficiência auditiva, não se identificou com essa representação, referida a identidade estigmatizada.

Isso mostra que a terceira idade pode ser uma etapa da vida de renascimento da identidade do consumidor, na qual o consumo é um dos meios pelos quais "os scripts culturais são contestados" (SCHAU; GILLY; WOLFINBARGER, 2009, p.255), com esse comportamento se opondo ao que é esperado pela sociedade e representado pelo mercado.

\subsection{Identidade da mulher e envelhecimento}

No contexto brasileiro, em especial o carioca, o corpo jovem, magro, sem marcas de estrias, de celulite, de flacidez e de rugas é altamente valorizado (GOLDENBERG, 2011). Em virtude disso, as mulheres na terceira idade são julgadas por se afastarem cada vez mais desse ideal estético de beleza relacionado à juventude (TUNALEY; WALSH; NICOLSON, 1999). Logo, os sinais de envelhecimento no corpo são considerados símbolos de estigma social (GOFFMAN, 2004).

Nesse sentido, os discursos da mídia encorajam as mulheres a assumirem a responsabilidade por sua aparência, e difundem novas técnicas de rejuvenescimento para mostrar que as marcas do tempo no corpo são consideradas como negligência por parte de quem se nega ao consumo de cosméticos ou de procedimentos cirúrgicos (CARDOSO, 2007; MALHEIROS JUNIOR; FREITAS, 2013). Esses discursos também difundem que o padrão de beleza está associado às mulheres jovens, o que leva as mulheres a quererem postergar os sinais do envelhecimento por meio da utilização de produtos e de serviços que auxiliem a esconder as marcas da idade (CABRAL, 2005; SZMIGIN; CARRIGAN, 2001).

O consumo de produtos e de serviços para cuidados com o corpo também está relacionado à importância que o corpo atualmente tem adquirido, visto que ele tem sido amplamente discutido e "valorizado como um componente discursivo que define e compõe a identidade da mulher" (VIEIRA, 2005, p.217). Assim, em uma sociedade que valoriza a juventude, a identidade seria construída tendo-a como referencial (THOMPSON; HIRSCHIMAN, 1995).

Logo, os sinais do envelhecimento constrangem a construção da identidade da mulher, pois, com o avanço da idade, ela se distancia cada vez mais do padrão de beleza que está relacionado à juventude (CLARKE, 2001; HURD, 2000). Por isso elas tendem a resistir às transformações relacionadas ao envelhecimento, investindo no uso de produtos e de serviços para melhorar a aparência do corpo (ALVES, 2006; MONTEMURRO; GILLEN, 2013).

\section{Método}

A orientação epistemológica adotada nesta pesquisa é a interpretativista. Segundo essa perspectiva, "a realidade social não existe em qualquer sentido concreto, mas é um produto da experiência subjetiva e intersubjetiva dos indivíduos" (MORGAN, 2005, p.65). 
Portanto, foi escolhida a abordagem qualitativa e descritiva para, do ponto de vista dos sujeitos, compreender o fenômeno, interpretá-lo e entender seus significados (MORESI, 2003). As informações obtidas na pesquisa são sobre o cotidiano das informantes, sobre seu comportamento e sobre suas experiências de consumo.

A seleção dos sujeitos foi embasada em três critérios: idade, gênero e região de residência. Assim, foram escolhidas mulheres na faixa dos 65 a 75 anos, moradoras da cidade e da região metropolitana do Rio de Janeiro. Para manter o anonimato das informantes os seus nomes foram trocados por codinomes.

O primeiro critério tem, como base, a Lei no 10.741 , de 01.10.2003, referente ao Estatuto do Idoso, que considera como pessoas idosas aquelas com idade igual ou superior a 60 anos. Esse corte, porém, não foi considerado nesse estudo, já que os indivíduos geralmente não se identificam com sua idade cronológica (BLAU, 1956). Por isso, nessa idade poderia não ser possível identificar comportamentos que indiquem a construção de uma identidade de idade da terceira idade. Com isso, o corte de 65 anos foi definido, por considerar que, nessa idade, as mulheres estariam de fato construindo uma identidade de idade da terceira idade, a qual se estabeleceria aos 75 anos de idade.

O segundo critério está pautado no fato de que, na cultura brasileira, o envelhecimento é mais julgado nas mulheres em virtude da aparência do seu corpo, do pouco conhecimento acerca das percepções e dos sentimentos sobre seus corpos, de como isso influencia na construção da sua identidade etária (HURD, 2000), e de como isso se relaciona com o consumo de produtos e de serviços.

Por fim, a cidade do Rio de Janeiro foi escolhida por ter um dos maiores índices de envelhecimento do Brasil (IBGE, 2012).

O levantamento de evidências foi realizado por meio de entrevistas semiestruturadas em profundidade com 11 mulheres residentes na região metropolitana da cidade do Rio de Janeiro (McCRACKEN, 1988), que permitiram a gravação em áudio das conversas, cujo conteúdo foi posteriormente transcrito, o que facilitou o processo de análise. Esse método mostrou-se adequado ao objetivo proposto, pois facultou entender o que essas pessoas pensam e como se sentem com relação ao envelhecimento, quais são os produtos e serviços utilizados por elas nessa fase da vida, e quais significados elas Ihes atribuem. Com isso, possibilitou compreender, do ponto de vista das informantes, como é construída a identidade de idade (McCRAKEN, 1988).

O roteiro de entrevista foi desenvolvido de acordo com o modelo grand tour (MCCRACKEN, 1988) na qual são feitas perguntas mais gerais relacionadas às categorias analíticas que surgiram da revisão teórica. Primeiramente buscou-se obter um perfil geral da entrevistada, saber sobre sua trajetória de vida, sua família, seu trabalho, sua rotina e suas atividades. A partir da sua fala foram introduzidas outras perguntas referentes às demais categorias.

As evidências foram analisadas por meio da análise de conteúdo, que se refere a "um conjunto de técnicas de análise das comunicações" (BARDIN, 2010, p.33) e que é organizada em três fases: 1) pré-análise; 2) exploração do material; 3) tratamento dos resultados, inferência e interpretação (BARDIN, 2010). Adotando esse método de análise, os dados obtidos por meio de entrevistas em profundidade foram lidos e foram destacadas as 
categorias de análise da teoria e que emergiram do campo; os dados textuais foram inseridos numa tabela onde pode-se perceber a frequência de ocorrência das categorias analíticas, a partir de então os dados foram interpretados.

\section{Resultado da Pesquisa}

Houve quatro categorias emergidas espontaneamente da análise interpretativa das evidências, expostas e analisadas a seguir: consumo e o enfrentamento do estereótipo da terceira idade; socialização; corpo e consumo; e identidade de idade na terceira idade.

\subsection{Consumo e o enfrentamento do estereótipo da terceira idade}

O discurso identitário da terceira idade foi construído pela sociedade associado a processo contínuo de perdas, de dependência, de incapacidade e de invalidez; ou seja, foram atribuídos significados sociais negativos e estigmatizantes aos indivíduos na terceira idade (DEBERT, 2000).

No entanto, nos discursos analisados surgiu a negação e o enfrentamento a uma identidade estereotipada e estigmatizada (GOFFMAN, 2004; PEREIRA; AYROSA, 2012) da terceira idade, ou seja, o enfrentamento da visão de que são mulheres debilitadas, doentes, incapazes. Assim, elas tentam desconstruir e comunicar uma identidade de idade na terceira idade positiva, diferente do estereótipo negativo construído socialmente sobre essa categoria etária. Para esse enfrentamento, as mulheres utilizam o consumo como um recurso: "Agora que eu estou vivendo. Agora eu faço ginástica, faço dança, né? [...] Saio mais. Eu vou para os bailes. É, vou toda semana, vou para os bailes com o meu namorado. Toda semana eu estou saindo." (Ângela, 71 anos).

Quando a gente é jovem tudo é muito difícil, né? Muita dificuldade pra tudo, depois que você vai ficando numa certa idade você vai [...] ficando numa situação definida, você tem mais condições pra tudo, né? Quando é jovem não aproveita nada, não vai a restaurante, não vai a nada, não tem dinheiro, vai fazer o quê? (Sandra, 73 anos).

Como enfatizam as informantes nos relatos anteriores, só a partir dessa fase da vida elas começaram a viver, sendo que, no seu discurso, viver significa consumir serviços e produtos que antes não era possível por falta de tempo, de recurso ou mesmo de oportunidade.

Esse ponto é recorrente na análise das evidências. As informantes relatam estar vivendo, atualmente, fase de grande satisfação pessoal, pois só agora têm a possibilidade de fazer e de comprar coisas para as quais, em fases passadas da vida, não tinham condições financeiras ou liberdade. Hoje, portanto, elas têm a possibilidade de consumir o que desejam, e isso parece levá-las a uma maior aceitação dessa fase da vida, pois atribuem significados positivos a este período de suas vidas. Nesse sentido, os significados atribuídos ao consumo de produtos e de serviços as auxiliam a construir uma identidade de idade mais positiva. Isso mostra que, para as informantes, a terceira idade pode ser uma etapa da vida de renascimento da identidade, na qual o consumo é um dos meios pelos quais os estereótipos negativos da idade são contestados (SCHAU; GILLY; WOLFINBARGER, 2009). 
No entanto, pontos negativos dessa idade também foram mencionados pelas informantes, relacionados a problemas adquiridos de saúde que elas atribuem serem decorrentes da idade: "Melhor idade em termos, né, porque tem o reumatismo, tem artrose [...] tem uns probleminhas chatos né, é uma dor aqui, uma dor ali, né, que infelizmente vêm mesmo". (Denise, 73 anos). Devido a esses problemas de saúde elas recorrem a serviços como fisioterapia, hidroginástica e ginástica, por meio dos quais realizam atividades físicas para a manutenção da saúde.

Assim, a preocupação em cuidar da saúde também parece estar relacionada aos fatos de querer permanecer sempre em atividade e de ser considerada pessoa útil. Nesse sentido, o consumo simbólico do corpo das mulheres da terceira idade por meio da prática de atividade física está atrelado à necessidade de se mostrarem úteis para sua família e para a sociedade, e, dessa forma, enfrentarem o estereótipo negativo da sua identidade de idade, relacionado à debilidade, à doença e à dependência. Esse ponto é corroborado por Pereira e Ayrosa (2012), que afirmam que grupos que têm sua identidade estigmatizada trabalham o consumo cultural do corpo para se distanciar do estereótipo e enfrentar o estigma social.

Isso pode ser percebido nos relatos das informantes que ressaltaram o quanto são ativas e quanta importância dão a isso. Foi notável perceber a satisfação que têm em permanecerem em constate atividade, o prazer que têm por ter condições de ajudar os filhos, inclusive no cuidado dos netos:

Eu trabalho o dia todo, eu lavo, eu passo, eu cozinho, eu vou pra Nova Iguaçu [...] tudo isso, ah eu vou, se precisar eu vou em reunião da minha neta quando a minha filha não pode ir, se meu genro tá doente eu vou pra lá, eu lavo roupa pra ela, passo, lavo a minha roupa, passo a minha roupa, faço compra, faço sacolão, minha vida é assim: não para não. (Miriam, 70 anos)

Nesse sentido, parece que a utilidade é um atributo valorizado entre elas. Uma das informantes fala enfaticamente dessa questão, fazendo um contraponto entre o termo velho e a utilidade: "Se você está andando, fazendo tuas coisas, tá cumprindo tua obrigação, não tá dependendo de ninguém [...] aquela pessoa não é velha [...] Velho é aquilo que já não presta pra nada [...]. Enquanto tá servindo não tá velho" (Denise, 73 anos). Este relato ilustra a rejeição ao termo "velho", que está fortemente associado à falta de utilidade social que o indivíduo passa a ter quando atinge a terceira idade.

Cabe destacar, ainda, que, ao comentar sobre os termos utilizados para referir-se à atual fase da vida no momento da entrevista, grande parte das informantes não pareceram à vontade com o fato de serem rotuladas e categorizadas com denominações relacionadas à idade - idosa ou de terceira idade. Isso parece estar relacionado ao estigma social que a terceira idade ainda carrega. Isso leva os indivíduos que se enquadram nessa categoria etária a serem vistos de maneira depreciativa, pois seu envelhecimento é considerado uma característica negativa; consequentemente, ele não é plenamente aceito em sociedade (GOFFMAN, 2004).

Por isso, elas reforçam que a terceira idade é uma fase na vida à qual podem ser atribuídos significados positivos, e rejeitam ativamente o estereótipo negativo da idade por meio do consumo (SCHAU; GILLY; WOLFINBARGER, 2009). 


\subsection{Socialização}

As academias de ginástica estão geralmente associadas às questões estéticas, à manutenção da forma física, à construção de um corpo "malhado", forte, saudável, dentre outros predicados valorizados e procurados pelos indivíduos. Por ser um ambiente de consumo onde os corpos estão ao mesmo tempo sendo trabalhados e expostos, a academia de ginástica pode ser denominada de "templo de culto ao corpo", visto que é considerada como um "local sagrado do consumidor que o frequenta com o intuito de cultuar seu corpo" (MARÇAL; SOUZA, 2007, p.5). Além disso, as academias são também ambientes em que se estabelecem sociabilidades, distinção social e identidade (CASTRO, 2007).

A busca por ambientes de consumo como academias de ginástica surgiu recorrentemente na análise das evidências. A procura por organizações que promovem a manutenção da saúde e do bem-estar, como pilates, fisioterapia e, principalmente, ginástica é quase predominante entre as informantes.

Porém, a escolha para realização de tais atividades não é feita unicamente por questões estéticas e de saúde: o que elas buscam nesses ambientes é o encontro e a socialização com seus pares, ou seja, com pessoas da mesma faixa etária: "Estou no grupo Renascer de idoso, no Gaffrée e Guinle. [...] Lá tem ginástica, tem fisioterapia, eu jogo conversa fora. Eu jogo conversa fora" (Fátima, 72 anos).

Como observado no relato acima, a motivação da informante para frequentar o local onde realiza atividade física se dá principalmente pela vontade e pelo prazer encontrados nesses ambientes de consumo, ao conviver e conversar com outras pessoas, ao cultivar amizades e ao se sentir integrada. Esses serviços são resignificados, pois, ao invés de considerar como um "templo de culto ao corpo", local onde o corpo é trabalhado para atingir a forma física ideal (MARÇAL; SOUZA, 2007), a informante atribui a esse ambiente um significado de lazer. Pode-se dizer, então, que o significado de "templo de culto ao corpo" seria mais convencionalmente adotado por jovens.

Esse ponto é corroborado por Holbrook e Hirschman (1987) e por Campbell (2001), que argumentam que a busca de prazer do consumidor é o que o leva às experiências de consumo. Além disso, cabe destacar que as experiências, os lugares, as pessoas com os quais nos sentimos ligados tornam-se parte de quem somos, e contribuem para a construção das nossas identidades (BELK, 1988). Nesse sentido, o convívio e a integração com os pares nas academias parecem contribuir para a construção de uma identidade de idade positiva para as informantes.

Relacionado a isso, muitas vezes o convívio com os mais jovens - os diferentes - nos ambientes de consumo surge nos relatos como algo que as faz sentirem-se desconfortáveis, constrangidas por não compartilharem dos mesmos dilemas, crenças e valores dessa fase da vida. Por outro lado, também são ambientes de consumo nos quais elas se sentem seguras por não estarem expostas a possíveis situações estigmatizantes.

Esse ponto é corroborado por Pereira e Ayrosa (2012), que afirmam que determinados ambientes de consumo são considerados uma espécie de refúgio para aqueles que sofrem estigma social, pois o encontro ali com seus pares faz com que se sintam livres para assumirem sua identidade. Da mesma forma, na presente pesquisa os clubes, as academias, as praças e os bailes onde se realizam as atividades direcionadas para a terceira 
idade parecem ser ambientes que proporcionam, às informantes, segurança, bem-estar, e, principalmente, socialização e consolidação de uma identidade de idade mais positiva.

\subsection{Corpo e consumo}

Foi percebido, a partir da análise das evidências, que uma das grandes preocupações das entrevistadas na terceira idade se refere à aparência. Por isso, passam a utilizar mais produtos e serviços para melhorar a aparência do corpo:

Ah, [você] começa a ser mais vaidosa, faz isso, faz aquilo e tudo que aparece a gente quer fazer pra ficar melhor, né? É... também, né, acho que faz parte da mulher, é porque já numa idade que se não se cuidar vai piorar, né? Olha, eu, pra dizer a verdade, eu uso assim uns cremes, vou à dermatologista, [...] e uso sabonetes, esses negócios tudo (Sandra, 73 anos).

Ao mencionar "se não cuidar vai piorar", a entrevistada parece utilizar os recursos citados para melhorar a aparência do corpo e postergar os sinais do envelhecimento. Tais investimentos no corpo, por parte das mulheres da terceira idade, parecem ocorrer devido à internalização do padrão estético social dominante, associado às mulheres jovens, o que torna difícil, para a mulher, aceitar o processo de envelhecimento (CABRAL, 2005; HURD, 2000; CLARKE, 2001; MONTEMURRO; GILLEN, 2013).

Para as informantes, por um lado é motivo de alegria viver muitos anos, mas, por outro lado, ver seus corpos envelhecendo e não ter controle sobre isso é motivo de tristeza. Por meio da análise dos relatos é possível perceber a importância do corpo e de sua aparência, pois, ao se depararem com seus corpos envelhecidos, sentem-se tristes, envergonhadas e por isso não gostam de ver sua imagem refletida no espelho: "Eu tento nem me lembrar, sabe? Porque aí a gente vai ficar triste, né? Nem me olhar no espelho eu pelada. Me olhar no espelho não gosto, entendeu? Muito chato, né? A gente vê que tudo está caído, que tudo está caído é horrível! " (Rita, 65 anos).

A imagem corporal de uma mulher é produto da interação entre a percepção que tem do seu corpo e dos ideais culturais de beleza existentes (HURD, 2000). Assim, por seus corpos não atenderem mais os ideais de beleza vigentes, relacionados à juventude, as informantes passam a atribuir significados negativos a seus corpos, como de tristeza e de vergonha.

Consequentemente, tendo em vista que a identidade pode ser construída por meio do corpo (SCHOUTEN, 1991; PEREIRA; AYROSA, 2012), as informantes rejeitam essa identidade de idade expressa em seus corpos marcados pelos sinais de envelhecimento, como pode ser percebido no relato de quem rejeita seu cabelo branco:

Eu pinto ele porque eu não gosto dele branco. Ah, não gosto! Aí eu de repente vou me sentir .... Não, não é me sentir velha, eu vou me achar na obrigação de usar essas roupas igual $[a]$ essas pessoas mais novas do que eu que se acham velhas. Porque vai falar: "Essa mulher de cabelo branquinho, ah, mas ela se acha". Mas não me acho mesmo! E aí eu vou brigar, então eu preferi e vou lá pintar. (Denise, 73 anos) 
Esse ponto do discurso de Denise parece estar relacionado à visão dualista do indivíduo que defende que a verdadeira identidade do indivíduo não pode ser constrangida pelo corpo em que o indivíduo está alojado (THOMPSON; HIRSCHMAN, 1995). No caso das informantes, elas revelaram que se sentem bem com seus corpos do ponto de vista físico por terem uma vida muito ativa e desempenharem todas as atividades diárias sem dificuldades; porém, na aparência, seus corpos já não refletem o que elas sentem.

Para enfrentar os sentimentos negativos, elas consomem produtos e serviços estéticos. Muitas das informantes se declararam vaidosas por assumirem dar muita importância à aparência e ao investimento nos cuidados com o corpo. A vaidade estimula o consumo de cosméticos e de tratamentos estéticos, pois, a partir do momento que percebe os efeitos dos recursos utilizados, a mulher vaidosa passa a buscar continuamente esses produtos e serviços (STREHLAU; CLARO; LABAN NETO, 2015).

Por meio da análise das evidências foi possível perceber que o significado do consumo estético para as informantes está relacionado à felicidade, ao bem-estar e a sentirse à vontade com seu corpo: "Ah, eu tenho muito cuidado. Tô dizendo que eu tô triste porque minha unha não tá pronta" (Miriam, 70 anos); "Hoje em dia o meu cuidado é o creme mesmo pra eu me sentir mais à vontade. A ideia que eu tenho é que [a pele] vai rachar, se eu não passar [creme hidratante], vai ficar tudo papelzinho... (risos). Como se fosse rachar tudo" (Luíza, 71 anos).

Essa preocupação com a aparência presente no discurso das informantes é corroborada por Hurd (2000), que afirma que, apesar de a terceira idade demandar maior atenção à saúde, a aparência continua sendo significativa para as mulheres dessa faixa etária, pois presenciam o culto à juventude e a ideia de que se pode escolher ter o corpo desejado.

Nesse sentido, também foi possível perceber que as informantes enfrentam o estereótipo negativo da idade e tentam construir uma identidade de idade mais positiva, relacionando idade à beleza: "Eu acho que uma mulher bonita depois dos 60 anos, ela tem que ter... se cuidar, [...] Então tem que prestar atenção no corpo, na comida, na roupa, no andar, andar bem vestida, adequadamente [...] Eu acho que tudo depende da boa aparência" (Rita, 65 anos).

Relacionado a isso, um dos termos mais mencionados pelas informantes, e que pareceu fundamental na construção da sua identidade de idade na terceira idade, foi "aceitar a idade". Significando que uma mulher que aceita a idade saberia se arrumar e se comportar da maneira que elas julgam adequada para sua faixa etária, e, portanto, poderia ser considerada bonita na terceira idade, esse termo apareceu de forma central nos discursos.

Além disso, o consumo estético surgiu nas evidências relacionado ao fato de as informantes não quererem ser tratadas de forma depreciativa, pois, em sociedade, os indivíduos que estão na terceira idade são desvalorizados: "Eu procuro ir sempre, ir arrumadinha [...] Senão eu vejo, quando vai mal arrumada, que eles não dão atenção. Então eu já procuro, entendeu? Vou arrumadinha" (Fátima, 72 anos).

Como ilustra esse relato, as preocupações com a aparência e com a arrumação aparecem nos discursos das informantes como um meio para enfrentar o estigma social e 
para construir uma identidade de idade mais positiva na terceira idade. Esse ponto é corroborado por Winterich (2007), que afirma que os cuidados com o corpo e a transformação da aparência são parte de uma estratégia para adquirir maior respeito e confiança, pois as pessoas que aparentam envelhecimento são desvalorizadas socialmente.

\subsection{Identidade de idade na terceira idade}

As categorias etárias são construções sociais que fragmentam o curso da vida em estágios formais, e que definem características, hábitos, valores para cada etapa da vida. Assim, atribuem identidades de idade aos indivíduos ao longo da vida (SILVA, 2008).

Nas entrevistas foi recorrente as informantes fazerem comparações entre a sua vida em fases passadas - juventude, idade adulta - e a atual, relatando o que consumiam e o que deixaram de consumir, ou o que atualmente consomem, mas que, em fases anteriores, não consumiam: "Depois que você vai ficando numa certa idade, você vai ficando numa situação definida, você tem mais condições pra tudo, né? Quando é jovem não aproveita nada, não vai a restaurante, não vai a nada, não tem dinheiro, vai fazer o quê? " (Sandra, 73 anos); "Eu não ponho minissaia, claro que eu não ponho coisa assim não, eu me visto da minha idade. Uso minha calça comprida, um blusão, roupa curta eu não visto não" (Elizabeth, 75 anos); "Quando eu era mais novinha, por exemplo, se eu usava um biquíni menor, hoje eu já uso um mais longuinho, não é? Também não vou botar tudo de fora" (Laura, 70 anos).

Ao mencionarem em seus discursos os termos "ficando numa certa idade", "eu me visto da minha idade", "quando eu era novinha", as informantes indicam diferenciação e categorização em termos de idade. Essa distinção parece ilustrar, claramente, que uma identidade de idade na terceira idade se construiu ou que está em processo de construção. $A$ identidade é, então, uma construção social que implica diferenciação, identificação e categorização dos indivíduos (WOODWARD, 2000; CUCHE, 1999).

A identidade como um fenômeno simbólico e social também tem implicações materiais e pode ser percebida por meio dos bens de consumo (WOODWARD, 2000). Esses últimos são carregados de significados culturais e podem ser utilizados pelos indivíduos, na construção de suas identidades, por meio da apropriação de suas propriedades significativas (McCRACKEN, 2003).

$\mathrm{Na}$ presente pesquisa esse ponto surge fortemente quando as informantes indicam, por meio dos significados atribuídos aos bens de consumo - como ilustram a mudança na maquiagem de Vânia ou no vestuário de Laura - a construção da sua identidade de idade na terceira idade, a categorização entre a jovem e a terceira idade, a antiga e a nova identidades: "Eu me pintava bem, agora eu só passo rímel, de vez em quando um batonzinho" (Vânia, 69 anos); "Então essas coisas assim eu já não uso mais, por exemplo, um short mais curto, eu uso um short mais comprido" (Laura, 70 anos).

As mudanças no consumo de produtos e de serviços parecem ser reflexo da imposição que as entrevistadas sentem para se adaptarem ao que a sociedade considera adequado para mulheres da terceira idade: "Eu fico, eu sinto até assim quando a pessoa quer se vestir igual uma mocinha, não tem condições mais, gente! A minha juventude já passou, agora eu tenho que me vestir, andar arrumadinha e me vestir decente" (Elizabeth, 75 anos). Ao demonstrar sua reprovação às mulheres da sua faixa etária que se vestem de 
maneira que considera inapropriada para a idade atual, Elizabeth na verdade está reproduzindo os significados culturais construídos pela sociedade, que estabelecem o que é adequado e inadequado para cada faixa etária.

Isso mostra que, por meio do consumo, elas estão construindo e comunicando, para o mundo, sua identidade de idade. No entanto, na análise de evidências destaca-se que as mulheres constroem uma identidade de idade positiva na terceira idade, diferente da identidade estigmatizada construída e difundida pelo mercado associada ao estereótipo negativo de que são feias, doentes, debilitadas, dependentes (BANHART; PEÑALOZA, 2013).

\section{Conclusão}

Ao analisar como mulheres entre 65 e 75 anos lidam com o estigma associado à terceira idade por meio de suas práticas de consumo, foi possível observar que atribuir significados positivos a essa fase da vida é o caminho para evitar que o estereótipo negativo recaia sobre elas, para enfrentar o estigma da terceira idade, e para construir uma identidade de idade na terceira idade mais positiva. Então, para reforçar essa identidade de idade mais positiva, elas ressaltam que são pessoas muito ativas, e mencionam o consumo como uma das principais fontes de satisfação pessoal nessa fase da vida.

A análise das evidências indicou, ainda, que os principais serviços consumidos pelas mulheres na terceira idade são aqueles relacionados à prática de atividade física, como no caso das academias da terceira idade e das aulas de dança. Além da sua função utilitária de melhoria da condição física, para elas a usufruição desses serviços está relacionada ao significado de utilidade: velho é sinônimo de inútil, atributo que elas não querem adquirir.

Além disso, esses serviços são relacionados ao significado de socialização. Tais significados são atribuídos pelas informantes na tentativa de construir uma identidade de idade mais positiva, relacionada à satisfação com a vida, ao prazer e à independência, que são significados opostos àqueles atribuídos socialmente à terceira idade.

Além disso, em virtude das marcas do tempo do corpo - rugas, flacidez, cabelos brancos - as mulheres afirmam nessa fase da vida se preocupar mais com os cuidados do corpo. Muitas vezes mencionados serem provocados pela vaidade, tais cuidados foram enfatizados pela importância e dedicação dadas aos seus corpos por meio do consumo de produtos e de serviços que melhorem a aparência.

Porém, é importante destacar que significados atribuídos ao consumo de produtos e de serviços estéticos estão relacionados à felicidade, à satisfação, à autoestima, ao sentir-se à vontade consigo mesma, à confiança e ao respeito que adquirem em sociedade. Essas mulheres acreditam que uma pessoa na terceira idade bem arrumada e com boa aparência é bem tratada. Isso mostra que esses significados estão relacionados ao enfrentamento do estigma, pois a sociedade valoriza a juventude em detrimento da terceira idade em função da aparência. Por isso, para enfrentar o estigma social, elas atribuem significados positivos ao consumo do corpo, e reforçam isso atrelando também a terceira idade à beleza.

Diante disso, pode-se concluir que felicidade, realização, utilidade, prazer, beleza e socialização são significados atribuídos ao consumo que contribuem para o enfrentamento do estigma da terceira idade e para construção da identidade de idade positiva de mulheres na faixa de 65 a 75 anos de idade. Nesse sentido, percebe-se que há, por parte dessas 
mulheres, esforço no sentido de construir uma identidade de idade que seja oposta àquela construída socialmente, com o significado do consumo ajudando a entender melhor como ocorre essa construção.

Isso pode ser percebido pelas comparações feitas pelas informantes entre sua identidade de idade atual e a da juventude. As diferenças entre ambos os momentos, mencionadas frequentemente, servem para destacar que a atual fase da vida é melhor que fases anteriores, com ênfase sempre nos pontos positivos presentes atualmente e nos pontos negativos do passado. Foi percebido, então, que a identidade de idade na terceira idade é construída numa relação dialógica entre o velho e o novo, o passado e o presente, saúde e doença, utilidade e inutilidade, liberdade e aprisionamento, belo e feio, vida e morte - ou seja, pontos positivos e negativos. Os pontos negativos, por sua vez, são enfrentados com significados positivos atribuídos ao consumo, e são transferidos à identidade de idade na terceira idade.

Para futuras pesquisas seria interessante realizar investigações qualitativas utilizando a relação entre agência do consumidor e estrutura social, para analisar até que ponto indivíduos na terceira idade reforçam ou enfrentam identidade de idade socialmente construída. Pesquisa também poderia ser realizada abordando as implicações e ou contribuições do feminismo para a identidade de idade que as mulheres tentam construir na terceira idade. Além disso, poderia ser investigada seleção de homens da mesma faixa etária, para entender como se sentem e como se comportam com relação ao envelhecimento, o que facultaria comparações de gênero para a identidade de idade na terceira idade.

\section{Referências}

ALVES, Andréa Moraes. Mulheres, corpos e performance: a construção de novos sentidos para o envelhecimento entre mulheres de camadas médias urbanas. In: LINS DE BARROS, Myrian (Org.). Família e Gerações. Rio de Janeiro: FGV, 2006. p.76-88.

ARNOULD, Eric. J.; THOMPSON, Craig J. Consumer Culture Theory (CCT): Twenty Years of Research. Journal of Consumer Research, Vol. 31, No. 4, p.868-882, Mar. 2005.

BALLSTAEDT, Ana Luiza Maia Pederneiras. Comportamento e Estilo de Vida da População Idosa e seu Poder de Consumo. Anais do Encuentro Latinoamericano de Diseño. Buenos Aires, Argentina, 2007. BARNHART, Michelle; PEÑALOZA, Lisa. Who Are You Calling Old? Negotiating Old Age Identity in the Elderly Consumption Ensemble. Journal of Consumer Research, Vol. 39, p.1133 - 1153, Apr. 2013. BARBOSA, Lívia; CAMPBELL, Colin(Orgs.). Cultura, consumo e identidade. Rio de Janeiro: FGV, 2006. BARDIN, Lawrence. Análise de conteúdo. 70 Ed. Lisboa/ Portugal: LDA, 2010.

BELK, Russell W. Possessions and the Extended Self. Journal of Consumer Research, Vol. 15, No. 2, p.139-168, Set. 1988.

BLAU, Zena S. Changes in Status and Age Identification. American Sociological Review, Vol. 21, No. 2, p.198-203, Abr. 1956.

CABRAL, Benedita E. L. Mulher e velhice. In: MOTTA, Alda B.; AZEVEDO, Eulália L.; GOMES, Márcia (Orgs.). Reparando a falta: dinâmica de gênero em perspectiva. Salvador: UFBA / Núcleo de Estudos Interdisciplinares sobre a mulher, 2005. P.53-61.

CAMPBELL, Colin. A ética romântica e o espírito do consumismo moderno. Rio de Janeiro: Rocco, 2001. 
CARDOSO, Áureo V. Velha é a vovozinha: Estratégias de marketing ensinando às mulheres novas formas de envelhecer. 2007, 143f. Dissertação (mestrado) - Programa de Pós-Graduação em Educação, Universidade Luterana do Brasil, Canoas, 2007.

CASTRO, Ana L. Culto ao corpo e estilos de vida: o jogo da construção de identidades na cultura contemporânea. Perspectivas, São Paulo, v. 31, p.137-168, Jan- Jun. 2007.

CLARKE, Laura H. Older Women's Bodies and the Self: The Construction of Identity in Later Life. CRSN/RCSA, V. 38, No. 4, p.441-464, 2001.

CUCHE, Dennys. A noção de cultura nas ciências sociais. Bauru: EDUSC, 1999.

DEBERT, Guita G. O significado da velhice na sociedade brasileira. Acta Paul Enf., São Paulo, V. 12, Número Especial, Parte 1, p.147-159, 2000.

FOUCAULT, Michel. A Ordem do Discurso. São Paulo: Loyola, 5a Ed. 1999.

GOFFMAN, Erving. Estigma: notas sobre a manipulação da identidade deteriorada. Rio de Janeiro: LTC, 2004.

GOLDENBERG, Miriam. Corpo, Envelhecimento e Felicidade na Cultura Brasileira. Contemporânea. Ed.18, Vol.9, No. 2, 2011.

GILLY, Mary C.; ZEITHAML, Valerie A. The Elderly Consumer and Adoption of Technologies. Journal of Consumer Research, Vol. 12, No. 3, p.353-357, Dec. 1985.

HOLBROOK, Morris B.; HIRSCHMAN, Elizabeth C. The Experiential Aspects of Consumption: Consumer Fantasies, Feelings, and Fun. Journal of Consumer Research, Vol. 9, No. 2, p.132-140, Sep. 1982.

HURD, Laura C. Older Women's Body Image and Embodied Experience: An Exploration. Journal of Women \& Aging, Vol. 12, No. 3-4, p.77-97, 2000.

IBGE. Instituto Brasileiro de Geografia e Estatística. Síntese dos Indicadores Sociais: Uma análise das condições de vida da população brasileira. Rio de Janeiro: IBGE, 2012.

IBGE. Instituto Brasileiro de Geografia e Estatística. Síntese dos Indicadores Sociais: Uma análise das condições de vida da população brasileira. Rio de Janeiro: IBGE, 2014.

MALHEIROS JUNIOR, Alberto; FREITAS, Silvane A. de. Envelhecimento e Consumo: As representações da velhice feminina no discurso midiático. Estudos Interdisciplinares do Envelhecimento, Porto Alegre, V. 17, No.1, p.275-291, 2012.

KELLY, Luciana T de S.; RIBAS, José R.; COSTA, Isabel de S. A. da. Atividades física, educativa e de dança: Um estudo dos valores dos consumidores idosos. In: XXXIV ENCONTRO NACIONAL DOS PROGRAMAS DE PÓS-GRADUAÇÃo EM ADMINISTRAÇÃO, 34, 2010, Rio de Janeiro. Anais...Rio de Janeiro, 2010.

KOZINETS, Robert V. Utopian Enterprise: Articulating the Meanings of Star Trek's Culture of Consumption. Journal of Consumer Research, Vol. 28,67-88, Jun. 2001.

MARÇAL, Maria C. C.; SOUZA, Angela C. R. O "olhar" de quem experiencia o marketing no fitness center: o templo de consumo do corpo pós-moderno. In: XXXIII Encontro Nacional dos Programas de Pós-Graduação em Administração, 33, 2007, Rio de Janeiro. Anais... Rio de Janeiro, 2007.

MCCRACKEN, Grant. Cultura e consumo: novas abordagens ao caráter simbólico dos bens e das atividades de consumo. Rio de Janeiro: MAUAD, 2003.

The long interview. Londres: Sage Publications, 1988.

MONTEMURRO, Beth; GILLEN, Meghan M. Wrinkles and Sagging Flesh: Exploring Transformations in Women's Sexual Body Image. Journal of Women \& Aging, Vol. 25, p.3-23, 2013.

MORESI, Eduardo (org.). Metodologia da Pesquisa. Brasília, 2003. Disponível em: http://ftp.unisc.br/portal/upload/com_arquivo/1370886616.pdf. Acesso em: 19 de junho de 2014.

MORGAN, Gareth. Paradigmas, metáforas e resolução de quebra-cabeças na teoria das organizações. RAE, vol. 45, no 1, p.58-71, Jan-Mar. 2005. 
NAM, Jinhee; HAMLIN, Reagan; GAM, Hae J., KANG, Ji H.; KIM, Jiyoung; KUMPHAI, Pimpawan, STARR, Cathy Starr; RICHARDS, Lynne. The fashion-conscious behaviours of mature female consumers. International Journal of Consumer Studies. p.102-108, 2006.

PEREIRA, Severino J. N.; AYROSA, Eduardo A. T. Corpos consumidos: cultura de consumo gay carioca. Organizações \& Sociedade - Salvador, v.19, n.61, p.295-313, Abr-Jun, 2012.

QUEZADO, Isabelle; MATOS, Fátima R. N.; SOUZA, Ellen C. Perfil de Consumo e Autopercepção do Idoso em Anúncios Televisivos. In: IV Congresso Internacional em Comunicação e Consumo, 4, 2014, São Paulo. Anais... São Paulo, 2014.

ROSENTHAL, Benjamin; BRITO, Eliane P. Z. Identity Projects of Mature Runners and Self Expression on Facebook. In: XXXIX Encontro Nacional dos Programas de Pós-Graduação em Administração, 39, 2015, Belo Horizonte. Anais... Belo Horizonte, 2015.

SANT'ANNA, M. J. G. UnATI, a velhice que se aprende na escola: um perfil de seus usuários. In: VERAS, R. (org.) Terceira idade: desafios para o terceiro milênio. Rio de Janeiro: Relume-Dumará, p.75-102, 1997.

SCAROBOTO, Daiane; FISCHER, Eileen. An institutional theory perspective on consumer quests for greater choice in mainstream markets. Journal of Consumer Research, Vol. 39, No. 6, p.1234-1257, Apr. 2013.

SCHAU, Hope J.; GILLY, Mary; WOLFINBARGER, Mary. Consumer Identity Renaissance: The Resurgence of Identity-Inspired Consumption in Retirement. Journal of Consumer Research, Vol. 36, p. $255-276$, Aug. 2009.

SCHOUTEN, John W. Selves in Transition: Symbolic Consumption in Personal Rites of Passage and Identity Reconstruction. Journal of Consumer Research. Vol. 17, p.412-425, Mar. 1991.

; McALEXANDER, James H. Subcultures of Consumption: An Ethnography of the New Bikers. Journal of Consumer Research, Vol. 22. p.43-61, Jun. 1995.

SILVA, Luna. Da velhice à terceira idade: o percurso histórico das identidades atreladas ao processo de envelhecimento. História, Ciências, Saúde - Manguinhos, v.15, No.1, p.155-168, Jan-Mar. 2008.

SLATER, Don. Cultura do consumo e modernidade. São Paulo: Nobel, 2002.

STREHLAU,Vivian I.; CLARO, Danny P.; LABAN NETO, Sílvio A. A vaidade impulsiona o consumo de cosméticos e de procedimentos estéticos cirúrgicos nas mulheres? Uma investigação exploratória. Revista de Administração, v.50, No.1, p.73-88, jan - mar. 2015.

SZMIGIN, Isabelle; CARRIGAN, Marylyn. Learning to love the older consumer. Journal of Consumer Behavior, Vol. 1, No. 1, p.22-34, Mar. 2001.

THOMPSON, Craig; HAYTKO, Diana L. Speaking of fashion discourses and the appropriation of countervailing cultural meanings, Journal of Consumer Research, vol. 24, p.15- 42, Jun. 1997.

TUNALEY, Jillian R., WALSH, Susan; NICOLSON, Paula. I'm not bad for my age: the meaning of body size and eating in the lives of older women. Ageing and Society, Vol. 19, p.741-759, 1999.

VIEIRA, Josênia A. A identidade da mulher na modernidade. D.E.L.T.A., 21: Especial, 2005, p.207-238.

WINTERICH, Julie A. Aging, Femininity, and the Body: What Appearance Changes Mean to Women with Age. Gend. Issues, Vol. 24, p.51-69, 2007.

WOODWARD, Kathryn. (2000). Identidade e diferença: Uma introdução teórica e conceitual In: SILVA, T. T. (Ed.), Identidade e diferença: A perspectiva dos estudos culturais. Petrópolis, RJ: Vozes. 